\title{
Audit of clopidogrel use in a medical clinic in a tertiary care hospital in Sri Lanka
}

\author{
Wijekoon $\mathbf{S}^{1}$, Wijekoon $\mathbf{C ~ N}^{1}$ \\ Journal of the Ceylon College of Physicians, 2016, 47, 82-85 \\ DOI: http://doi.org/10.4038/jccp.v47i2.7788
}

Key words : stroke, knowledge, awareness, developing country, Sri Lanka

\section{Introduction}

Clopidogrel is a widely used anti-platelet agent. The active metabolite of clopidogrel blocks the interaction between adenosine diphosphate and P2Y12 receptor and prevents ADP mediated activation of aglycoprotein GPIIb/IIla complex and thereby inhibits platelet aggregation. It is an irreversible inhibition.

Clopidogrel is used as monotherapy or in combination with aspirin in management of cardiovascular diseases (CVD); namely coronary artery disease (CAD), ischaemic stroke and transient ischaemic attack (TIA). Several large multicentre clinical trials have shown the benefits of clopidogrel in cardiovascular diseases. ${ }^{1,2}$ American Heart Association (AHA), American College of Cardiology (ACC) and American Stroke Association (ASA) guidelines $3,4,5,6,7,8,9$ have given clear evidene based recommendations for clopidogrel use.

The guidelines strongly recommend to start dual antiplatelet therapy (DAPT) with clopidogrel and aspirin after an acute coronary syndrome (ACS). Maximum recommended duration of DAPT after an ACS managed without percutaneous intervention is 12 months. After a minor stroke/TIA, DAPT with clopidogrel and aspirin might be considered within 24 hours and continued for 21 days; however the strength of this recommendation is weak. Clopidogrel monotherapy is generally recommended for secondary prevention of CVD only if there is aspirin intolerance. In primary prevention of CVD clopidogrel is not recommended. A summary of these recommendations is shown in table 1.

However clopidogrel use is associated with an increased risk of major bleeding including haemorhagic stroke and gastro-intestinal bleeding. This risk is further increased when it is combined with aspirin. Specially, long term DAPT confers a significantly higher risk of haemorrhagic complications. ${ }^{10,11,12,13}$ Therefore it is extremely important to ensure that clopidogrel is prescribed appropriately for recommended indications and it is not used beyond the recommended duration.

\footnotetext{
${ }^{1}$ Faculty of Medical Sciences, University of Sri Jayewardenepura.

Corresponding author: SW

E-mail: sanjeewa_wijekoon@sjp.ac.Ik
}

Data about prescription pattern of clopidogrel in the local setting will be valuable to formulate a plan to minimize unnecessary use of clopidogrel. However a literature survey did not reveal any previous publications about clopidogrel use in Sri Lanka.

\section{Objective}

The objective of the audit was to find out whether clopidogrel use was appropriate as monotherapy or as a part of DAPT with regard to indication and duration of therapy, among patients who were on clopidogrel in the audit setting.

\section{Methods}

\section{Audit setting and time period}

We audited the process of care with regard to clopidogrel use at a follow-up medical clinic of a tertiary care hospital from May 2013 to March 2014.

\section{Practice standards}

The practice standards used for this audit were evidence based recommendations in most up to date AHA, ACC and ASA guidelines for management of coronary artery disease (CAD), ischaemic stroke and transient ischaemic attack (TIA) and primary prevention of CVD. ${ }^{3,4,5,6,7,8,9}$

\section{Audit criteria}

The audit criteria we used are given below.

- Among patients who were on clopidogrel monotherapy, the percentage that received it for correct indication

- $\quad$ Among patients who were on DAPT (clopidogrel + aspirin) the percentage that received it for correct indication

- $\quad$ Among patients who were on DAPT (clopidogrel + aspirin) for correct indication, the percentage that received it for correct duration

- Among all patients who were on clopidogrel as monotherapy or as a part of DAPT, the percentage that received it for correct indication and duration (i.e percentage of patients in whom clopidogrel was used appropriately) 
Table 1. Summary of recommendations for clopidogrel use

\begin{tabular}{|c|c|c|}
\hline Indication & $\begin{array}{l}\text { Clopidogrel monotherapy } \\
\text { (Class of recommendation, } \\
\text { Level of evidence) }\end{array}$ & $\begin{array}{l}\text { Dual Antiplatelet Therapy } \\
\text { [aspirin + clopidogrel] } \\
\text { (Class of recommendation, } \\
\text { Level of evidence) }\end{array}$ \\
\hline $\begin{array}{l}\text { STEMI managed with } \\
\text { fibrinolytic therapy alone } e^{3,9}\end{array}$ & Not commented & $\begin{array}{l}\text { At least } 14 \text { days }(I, A) \\
\text { Up to } 12 \text { months }(I, C)\end{array}$ \\
\hline $\begin{array}{l}\text { STEMI managed with } \\
\text { primary PCI / PCI after } \\
\text { fibrinolytic therapy }{ }^{3,9}\end{array}$ & Not commented & At least 12 months $(\mathrm{I}, \mathrm{B})$ \\
\hline $\begin{array}{l}\text { STEMI managed with } \\
\text { medical therapy alone } \\
\text { (without PCl or fibrinolytic } \\
\text { therapy) }\end{array}$ & Not commented & At least 12 months $(\mathrm{I}, \mathrm{B})$ \\
\hline $\begin{array}{l}\text { NSTE-ACS managed } \\
\text { without } \mathrm{PCl}^{4}\end{array}$ & $\begin{array}{l}\text { Recommended in } \\
\text { aspirin intolerance }(\mathrm{I}, \mathrm{B})\end{array}$ & Up to 12 months $(\mathrm{I}, \mathrm{B})$ \\
\hline $\begin{array}{l}\text { NSTE-ACS managed } \\
\text { with } \mathrm{PCl}^{4,9}\end{array}$ & Not commented & At least 12 months $(\mathrm{I}, \mathrm{B})$ \\
\hline $\begin{array}{l}\text { Stable CAD medical } \\
\text { management } 5,9\end{array}$ & $\begin{array}{l}\text { Recommended in } \\
\text { aspirin intolerance }(\mathrm{I}, \mathrm{B})\end{array}$ & Not recommended \\
\hline $\begin{array}{l}\text { Stable CAD managed } \\
\text { with } \mathrm{PCl}^{5,9}\end{array}$ & Not recommended ${ }^{* *}$ & $\begin{array}{l}\text { At least } 6 \text { months for DES }(I, B) \\
\text { Minimum of } 1 \text { month for BMS }(I, A)\end{array}$ \\
\hline $\begin{array}{l}\text { Ischaemic stroke/ transient } \\
\text { ischaemic attack }\end{array}$ & $\begin{array}{l}\text { Recommended }(I l a, B) \\
\text { Recommendation is less } \\
\text { stronger than for aspirin }(I, A)^{\star \star *}\end{array}$ & $\begin{array}{l}\text { Recommended only for a } \\
\text { selected group of patients(IIb, B })^{\star \star \star \star}\end{array}$ \\
\hline Primary prevention of CVD ${ }^{7,8}$ & Not recommended & Not recommended \\
\hline
\end{tabular}

STEMI- ST Elevation Myocardial Infarction, PCl- percutaneous intervention, NSTE-ACS- Non ST Elevation Acute Coronary Syndrome, CAD- coronary artery disease, DES - drug-eluting stent, BMS - bare-metal stent, DAPT - dual antiplatelet therapy

*hypersensitivity or major gastrointestinal intolerance

${ }^{* *} \mathrm{PCI}$ with coronary stenting (DES or BMS) should not be performed if the patient is not likely to be able to tolerate and comply with dual antiplatelet therapy for the appropriate duration of treatment

${ }^{* *}$ Aspirin monotherapy (Class I; Level of Evidence A) or the combination of aspirin 25 mg and extended-release dipyridamole 200 mg twice daily (Class I; Level of Evidence $B$ ) is indicated as initial therapy after TIA or ischemic stroke for prevention of future stroke. Clopidogrel (75 mg) monotherapy is a reasonable option for secondary prevention of stroke in place of aspirin or combination aspirin/dipyridamole (Class Ila; Level of Evidence B). This recommendation also applies to patients who are allergic to aspirin.

${ }^{* * \star *}$ The combination of aspirin and clopidogrel might be considered for initiation within 24 hours of a minor ischemic stroke or TIA and for continuation for 21 days (Class I/b; Level of Evidence B). The combination of aspirin and clopidogrel, when initiated days to years after a minor stroke or TIA and continued for 2 to 3 years, increases the risk of haemorrhage relative to either agent alone and is not recommended for routine long-term secondary prevention after ischemic stroke or TIA (Class III; Level of Evidence A).

\section{Audit standards}

The standard we set for the audit was to achieve $100 \%$ for each of the audit criteria.

\section{Data collection}

Consecutive sampling was done and data collection was carried out prospectively. Prescription cards of all patients attending the clinic were examined to identify patients who were on clopidogrel. There were no exclusion criteria. After obtaining informed consent, data was collected from all those who were on clopidogrel. Data related to clopidogrel use were obtained using clinic record books and patient interviews by dedicated MBBS qualified research coordinators. Indication to start clopidogrel, duration of treatment up to the time of audit, whether clopidogrel was given in combination with other 
Table 2. Summary of the results according to audit criteria

\begin{tabular}{lc}
\multicolumn{1}{c}{ Audit criterion } & Result \\
\hline $\begin{array}{l}\text { Among patients who were on clopidogrel monotherapy, the percentage } \\
\text { that received it for correct indication }\end{array}$ & $68.4 \%(26 / 38)$ \\
Among patients who were on DAPT (clopidogrel + aspirin) the percentage & $88.6 \%(86 / 97)$ \\
that received it for correct indication & $45.3 \%(39 / 86)$ \\
Among patients who were on DAPT (clopidogrel + aspirin) for correct indication, \\
the percentage that received it for correct duration \\
$\begin{array}{l}\text { Among all patients who were on clopidogrel as monotherapy or as a part } \\
\text { of DAPT, the percentage that received it for correct indication and duration } \\
\text { (i.e percentage of patients in whom clopidogrel was used appropriately) }\end{array}$ \\
\hline
\end{tabular}

anti-platelet medications and history of aspirin intolerance (aspirin allergy or severe gastro-intestinal side effects) were recorded in pre-tested paper based interviewer administered questionnaire.

\section{Ethics}

Ethical clearance for the audit was obtained from Ethics Review Committee of Faculty of Medical Sciences, University of Sri Jayewardenepura. Informed consent was taken from all participants of the audit. In patients in whom clopidogrel use was found to be inappropriate, the necessary changes to medication regimen was done after consultation with the attending medical team.

\section{Data analysis}

Existing practice of clopidogrel use in the audit setting was compared with the practice standard described above. The results are presented as proportions and percentages.

\section{Results}

Out of 1200 patients attending the clinic 135 were on clopidogrel. $60.7 \%$ of them were men. Mean age of the population was 63.6 years (range $41-88$ years).

38 patients (28\%) were on clopidogrel monotherapy and 97 patients (72\%) were on clopidogrel as a part of DAPT. Aspirin was the anti-platelet drug used in combination with clopidogrel in all occasions.

Out of the 97 patients who were on clopidogrel as part of DAPT, $86(88.6 \%)$ had a history of ACS. Among those with no history of ACS, 7 patients had a history of ischaemic stroke and 1 patient had stable CAD. 3 patients were on DAPT for primary prevention of CVD. In the audit cohort, there were no patients who had undergone percutaneous coronary intervention or coronary artery by-pass grafting.

Out of the 86 patients on DAPT following ACS, 47
(54.7\%) were on it for more than 12 months (range: 13 98 months) which is beyond the recommended duration. In the 7 patients who had a history of ischaemic stroke, duration of DAPT ranged from 10 to 58 months.

Out of 38 patients who were on monotherapy, 35 were on clopidogrel for secondary prevention of CVD (post ACS - 20 patients, post stroke - 8, stable CAD - 7). However, 9 (post ACS - 4 patients, post stroke - 4, stable CAD - 1) of them did not have any evidence of aspirin intolerance after a thorough evaluation of medical records and a detailed history taken by research coordinators. 3 patients were on clopidogrel monotherapy for primary prevention of CVD.

The results are further illustrated in figure 1. Summary of the results according to the audit criteria are given in table 2.

\section{Discussion}

Overall, in 65 patients out of 135 (48.1\%), clopidogrel use was in keeping with recommendations of AHA, ACC and ASA guidelines. This included patients on DAPT for less than 12 months after an ACS and patients on clopidogrel monotherapy for secondary prevention of CVD who had a history of aspirin intolerance. The appropriate use of clopidogrel in the audit setting was far below the set audit standard of $100 \%$.

Out of the 70 patients in whom clopidogrel use was inappropriate, in 58 (43\%) clopidogrel should have been stopped. Majority of them were patients who were on DAPT after an ACS where clopidogrel was continued beyond 12 months. The other groups were those with a history of stroke where DAPT was continued beyond 21 days, patients on DAPT for stable coronary artery disease and patients on DAPT for primary prevention of CVD. In 12 patients (9\%) aspirin should have been used instead of clopidogrel. This included patients who were on clopidogrel for primary prevention of CVD and those who were on it for secondary prevention of CVD without any evidence of aspirin intolerance. 
Clopidogrel use in this study setting was unsatisfactory. Out of the four audit criteria none met the audit standards. The criterion closest to the audit standard was using DAPT for correct indication. The most important criterion which is the overall appropriate use of clopidogrel was far below the audit standard; in $52 \%$ of audit subjects clopidogrel use was not in keeping with evidence based guideline recommendations. Main contributing factor for that was continuation of DAPT beyond 12 months in patients who have had an ACS (35\%).

This audit setting was a follow-up medical clinic where almost all patients had at least one hospital admission. Information about the patient, including details of the initial and subsequent hospital admissions and the starting date of clopidogrel were clearly mentioned in the clinic record books. However it was noted that medical officers repeated the prescription of the previous month without considering the starting date of clopidogrel, leading to continuation of DAPT beyond recommended duration. A study done in East London UK has reported automated repeat prescription and use of a pre-printed "tick-box" type list contribute to continuation of clopidogrel beyond the recommended duration ${ }^{14}$. However it was not the case in this setting.

In this audit setting $17 \%$ of patients were on clopidogrel for indications not supported by evidence based guidelines. Inadequate knowledge of the initial prescriber and continuation of the initially prescribed medication without regular re-evaluation are likely factors contributing to that.

Following the audit, several steps were taken to correct the deficiencies detected. The audit findings were presented to all the prescribers of the unit during a regular monthly clinical meeting. Recommendations in the guidelines used as practice standards, were also presented and discussed to improve the prescribers' knowledge. Algorithms for use of antiplatelet drugs in ACS and ischaemic stroke were developed and displayed in the wards and clinic. Since continuation of dual anti-platelet therapy beyond 12 months in patients who had an ACS was the main contributor for inappropriate use of clopidogrel, it was decided to indicate clearly, in a different colour or in highlighted form, the expected end date of clopidogrel in the diagnosis card and clinic record book of patients with ACS. The clinic appointment system was changed in a way that the consultant physician in charge of the clinic sees 20 follow up patients on each clinic day in order to ensure that the patients' medication regimen is regularly reviewed by a consultant. To establish the success of these remedial measures a re-audit will be conducted in 2017.

\section{Conclusions and Recommendations}

This audit done at a follow-up medical clinic in a tertiary care hospital indicated that clopidogrel was inappropriately used in a large proportion of patients. The main contributing factor was continuation of dual anti-platelet therapy beyond 12 months in patients who have had acute coronary syndromes. Several remedial measures have been taken at the audit site and a reaudit is planned. Conduct of similar audits at different hospital settings is recommended to identify the deficiencies in order to improve patient care.

\section{References}

1. Gent M, Beaumont D, Blanchard J, et al. A randomised, blinded, trial of clopidogrel versus aspirin in patients at risk of ischaemic events (CAPRIE). Lancet 1996; 348: 1329-39.

2. The Clopidogrel in Unstable Angina to Prevent Recurrent Events Trial Investigators. Effects of Clopidogrel in Addition to Aspirin in Patients with Acute Coronary Syndromes without ST-Segment Elevation. N Engl J Med 2001; 345: 494-502.

3. O'Gara PT, Kushner FG, Ascheim DD, et al. 2013 ACCF/ AHA STEMI Guideline. JACC 2013; 61: e78-140.

4. Amsterdam EA, Wenger NK, Brindis RG, et al. 2014 AHA/ ACC NSTE-ACS Guideline. JACC 2014; 64: e139-228.

5. Fihn SD, Blankenship JC, Alexander KP, et al. 2014 Stable ischemic heart disease Focused Update. JACC 2014; 64: 1929-49.

6. Kernan WN, Ovbiagele B, Black HR,et al. Stroke prevention in patients with stroke and TIA. Stroke 2014; 45: 2160-236.

7. Pearson TA, Blair SN, Daniels SR, et al. Primary prevention of cardiovascular disease Circulation 2002; 106: 388-91.

8. Meschia JF, Bushnell C, Boden-Albala B, et al. Guidelines for the Primary Prevention of Stroke. Stroke 2014; 45: 3754-832.

9. Levine GN, Bates ER, Bittl JA, et al. Focused Update on Duration of Dual Antiplatelet Therapy. Circulation 2016; 133: $1-57$

10. Zhang Q, Wang C, Zheng M, Li Y, Li J, Zhang L, Shang Z, Yan C. Aspirin plus Clopidogrel as Secondary Prevention after Stroke or Transient Ischemic Attack: A Systematic Review and Meta- Analysis. Cerebrovasc Dis. 2015; 39: 13-22.

11. Rodríguez LAG, Lin KJ, Hernandez-Diaz S, Johansson S. Risk of Upper Gastrointestinal Bleeding With Low-Dose Acetylsalicylic Acid Alone and in Combination With Clopidogrel and Other Medications. Circulation 2011; 123 : 1108-15.

12. Diener HC, Bogousslavsky J, Brass LM, et al. Aspirin and clopidogrel compared with clopidogrel alone after recent ischaemic stroke or transient ischaemic attack in highrisk patients (MATCH): randomised, double-blind, placebo-controlled trial. Lancet 2004; 364: 331-7.

13. Liyanage $\mathrm{CAH}$, Jayaweera KKDG, Deen KI. Clopidogrel and surgery: "be aware" The Sri Lanka Journal of Surgery 2010; 28: 1-4.

14. Lo T. An Audit of Prescribing Practice for Clopidogrel in Primary Care. Cardiology and Respiratory Medicine 2009; 1: 12-15. 